\title{
Trade, Wages, and Specific Factors
}

\author{
Indro Dasgupta* Thomas Osang Th $^{+\frac{+}{*}}$
}

Southern Methodist University

September 1, 2000

Keywords: specific factors, skill premium, trade, factor endowments, technological change

JEL classification : F16, J31

${ }^{*}$ Southern Methodist University, Department of Economics, Dallas, TX 75275. Tel : (214) 768-2235, Fax : (214) 768-1821, E-mail : idasgupt@post.smu.edu

${ }^{\dagger}$ Southern Methodist University, Deparment of Economics, Dallas, TX 75275. Tel : (214) 768-4398, Fax : (214) 768-1821, E-mail : tosang@mail.smu.edu

$\ddagger$ We would like to thank seminar participants at the SETI and MEA Meetings as well as at the 8th World Congress of the Econometric Society for helpful comments and suggestions. 


\begin{abstract}
In this paper, we use a multi-sector specific factors model with sector-specific capital and two mobile factors, production and non-production labor, to examine the effects of trade, technology, and factor endowments on the skill premium in U.S. manufacturing industries. A key feature of this model is that factor-price insensitivity does not hold, and thus endowment changes and factor-specific technological change affect relative factor returns, and hence the skill premium. Using this model and data for the U.S. manufacturing sector from 1958-92, we calculate changes in the skill premium and then carry out a decomposition to identify the changes caused by product price changes (trade), technological progress, labor and capital endowment changes. We find the model to be a fairly accurate predictor of both the direction and magnitude of changes in the skill premium. The decomposition reveals that trade effects, working through product price changes, caused the skill premium to increase during the '70s and ' $80 \mathrm{~s}$, while changes in capital endowments (new investments) had a positive effect on the skill premium throughout the entire sample period. Technological change, both sector and factor-specific, also had a positive impact on the premium. Finally, changes in relative labor endowments caused a decline in the premium throughout the sample period.
\end{abstract}




\section{Introduction}

The sharp rise in the skill premium in the United States and other industrialized countries since the early ' 80 s has been a subject of intense study by economists ${ }^{1}$. This research, focussing primarily on the U.S., has examined whether supply-side factors such as changes in the supply of skilled and unskilled workers or demand-side factors such as total factor productivity (TFP) growth, skillbiased technological change (SBTC), and globalization were responsible for the observed rise in the skill premium ${ }^{2}$. A related question concerns the relative strength of each of the above factors. Studies that have been primarily concerned with the effects of globalization on relative wages have typically used the Heckscher-Ohlin (H-O) model of a small open economy as the theoretical framework. One of the main results of the H-O model is the Stolper-Samuelson (S-S) theorem. The strong $2 \times 2$ version of this theorem predicts that, for skilled-labor abundant countries, product price changes caused by a reduction in trade barriers will induce wage gains for skilled and losses for unskilled workers. An empirical implementation of the S-S theorem, the so-called "mandated-wage regression' method, has been used in a number of studies on relative wages in the U.S. and other developed countries (Leamer [22], Baldwin and Cain [2], Haskel and Slaughter [11]).

The choice of the H-O model as the theoretical framework, however, is not without shortcomings. First, the critical assumption behind the S-S theorem's unambiguous predictions about relative wage movements is the perfect mobility of factors between sectors. While this assumption can be justified as a valid long-run characterization of an economy, its validity in the short-run is rather questionable. In the short-run, it is likely that some factors are sector specific and thus immobile. In this case, the predictions of the S-S theorem would no longer be valid, a result confirmed in the well-known study by Magee [23]. Second, as pointed out by Engerman and Jones [8], in a

\footnotetext{
${ }^{1}$ The skill premium is defined as the wage gap between skilled and unskilled workers.

${ }^{2}$ For a survey of this research, see Cline [6].
} 
small open economy H-O model, factor endowments and SBTC do not affect relative wages. This 'factor-price insensitivity' implies that empirical studies based on the small open economy version of the H-O model can only analyze the effects of product price changes and TFP growth on relative wages, but not the effects of endowment changes and SBTC.

In this paper, we address both shortcomings of the $\mathrm{H}-\mathrm{O} /$ mandated-wage regression approach by analyzing a multi-sector Specific Factors (SF) model ${ }^{3}$. The SF model assumes at least one immobile sector-specific factor, typically capital, which makes it better suited to characterize an economy in the short run. In addition, 'factor-price insensitivity' does not hold in this model ${ }^{4}$. Even in the small open economy version of the SF model, changes in the endowment with skilled and unskilled workers, changes in capital endowments (i.e., new investment) as well as factor-specific technological change, in addition to product price changes and TFP growth, can affect relative wages 5 .

Our model is an extension of the multi-commodity specific factors model analyzed by Jones [13]. We formulate a small open economy version of the SF model with capital as the immobile factor, and skilled and unskilled workers as the mobile factors. As in the mandated wage regression approach, we identify trade effects through changes in product prices. Due to the small open economy assumption, movements in product prices are considered exogenous. The solution to this multi-sector SF model yields changes in equilibrium factor prices as functions of endowment changes, changes in product prices, TFP, and factor-specific technological progress. Using estimates of factor-demand elasticities and data on U.S. manufacturing industries from 1958 to 1992 , we calculate the change in the skill premium predicted by the model and compare the predicted with

\footnotetext{
${ }^{3}$ Analyzing the issue of trade and wage inequality in a SF framework was strongly suggested by Leamer [22]. Kohli [17] estimates a SF model for the U.S. economy and shows that this model has greater explanatory power than the $\mathrm{H}-\mathrm{O}$ model. However, he does not consider the issue of rising skill premium in his paper.

${ }^{4}$ For further properties of this model, see Jones [12].

${ }^{5}$ Since it is factor-specific technological change rather than SBTC that is readily defined in the multi-sector SF model, we will use the former rather than the latter expression from now on.
} 
the actual change ${ }^{6}$. We then calculate the contribution to the predicted change by four important exogenous components: trade, labor endowment, capital endowment, and technical change.

Our main results are as follows. First, we find the predictions of the SF model to be fairly accurate in both direction and magnitude, in particular in the early sample periods. Second, trade operating through product price changes had a positive impact on the skill premium, in particular during the later half of the sample. Third, increases in the supply of skilled workers relative to unskilled workers worked towards lowering the skill premium, while changes in capital endowment had a positive effect throughout the sample period. Fourth, the combined impact of all technological change measures on the skill premium was positive, but moderate. Finally, sensitivity tests reveal that our results are robust to an alternative measure of TFP.

Our empirical results can be related to previous findings of the literature studying the rise in the skill premium. With the labor economics literature, as exemplified by papers such as Berman, Bound and Griliches [3], Berman, Bound and Machin [4], and Krueger [19], we share the conclusion that technological change and new investments in capital goods are driving forces behind the increase in skill premium in the U.S. economy. Similarly, like a number of papers from the empirical trade literature ${ }^{7}$, such as Sachs and Shatz [26], Leamer [22], Krueger [20], and Dasgupta and Osang [7], we find support for the hypotheses that trade effects working through product price changes contributed to the actual rise in the skill premium. Therefore, while our approach differs from either of the two strands, the result that technological change, new investments, and trade are mainly responsible for the rise in the skill premium in U.S. manufacturing industries since the early ' $80 \mathrm{~s}$, is in line with the findings from each strand.

The paper is organized as follows. The theoretical model is derived in section 2 . In sections 3

\footnotetext{
${ }^{6}$ It is still an open question whether the U.S. can be considered a small open economy. However, recent research by Magee et al [24] convincingly rejects the hypothesis that the U.S. is a 'large open economy'.

${ }^{7}$ For instance, Leamer designates the ' $70 \mathrm{~s}$ as the 'Stolper-Samuelson decade', while Krueger finds the same effects for 1989-94. See Slaughter [27] for a detailed review of these and other related papers.
} 
and 4 we discuss data issues and empirical results, respectively. Sensitivity results are presented in section 5. Section 6 concludes.

\section{The Model}

We consider a small open economy which produces $m$ commodities in as many sectors of production. There are three factors of production in each sector: sector-specific capital $(\mathrm{K})$, production labor $(\mathrm{P})$, and non-production labor (NP). Capital is immobile, while both types of labor inputs are mobile between sectors. Production functions are continuous, twice differentiable, quasi-concave and exhibit diminishing returns to all factors. Domestic prices are exogenous and are assumed to be affected by globalization shocks. Production sectors are indexed by $j=1, \ldots ., m$, and factors of production are indexed by $i=K, P, N P$. Aggregate factor endowments are denoted by $V_{i}$. Thus, there are a total of $m+2$ factors of production in the economy. Let $a_{K j}, a_{P j}, a_{N P j}$ denote the quantity of the three factors required per unit of output in the $j t h$ sector, i.e., $a_{i j}$ denotes the unit input coefficient of factor $i$ in sector $j$. Let $p_{j}, q_{j}$ represent price and output of the $j t h$ sector, and $r_{j}, w_{P}$, and $w_{N P}$ denote factor prices, with $r_{j}$ being the returns to capital in the $j t h$ sector. In what follows, we describe the equilibrium conditions for this model. The factor market clearing conditions are given by

$$
\begin{gathered}
a_{K j} q_{j}=V_{K j} \quad \forall j \\
\sum_{j} a_{P j} q_{j}=V_{P} \\
\sum_{j} a_{N P j} q_{j}=V_{N P}
\end{gathered}
$$

Sectoral unit input coefficients are variable and are subject to technological change. In particular, changes in these coefficients can be decomposed as in Jones $[14]^{8}$ :

\footnotetext{
${ }^{8}$ Here $\widehat{X}=d X / X$.
} 


$$
\widehat{a_{i j}}=\widehat{c_{i j}}-\widehat{b_{i j}} \forall j, i
$$

Here, $\widehat{c_{i j}}$ denotes changes in input coefficients as a result of changes in relative factor prices, while $\widehat{b_{i j}}$ denotes exogenous technological progress (i.e., the reduction in the amount of factor $i$ required to produce one unit of output $j$ ). Holding technology constant, input demands in each sector depend upon factor prices:

$$
\begin{gathered}
c_{K j}=c_{K j}\left(r_{j}, w_{P}, w_{N P}\right) \quad \forall j \\
c_{P j}=c_{P j}\left(r_{j}, w_{P}, w_{N P}\right) \quad \forall j \\
c_{N P j}=c_{N P j}\left(r_{j}, w_{P}, w_{N P}\right) \quad \forall j
\end{gathered}
$$

The sectoral zero-profit conditions are given by

$$
p_{j}=a_{K j} r_{j}+a_{P j} w_{P}+a_{N P j} w_{N P} \forall j
$$

Using hat-calculus and denoting factor shares by $\theta$, equation (2.8) can be written as

$$
\widehat{p_{j}}=\theta_{K j} \widehat{r_{j}}+\theta_{P j} \widehat{w_{P}}+\theta_{N P j} \widehat{w_{N P}}-\Pi_{j} \forall j
$$

where $\Pi_{j}=\sum_{i} \theta_{i j} \widehat{b_{i j}}$ is a measure of technical change in sector $j$. To derive (2.9) we made use of the Wong-Viner Envelope Theorem, which implies that:

$$
\theta_{K j} \widehat{c_{K j}}+\theta_{P j} \widehat{c_{P j}}+\theta_{N P j} \widehat{c_{N P j}}=0 \forall j
$$

Using hat calculus, the factor market clearing equations (2.1)-(2.3) can be rewritten as

$$
\begin{gathered}
\widehat{q_{j}}=-\widehat{c_{K j}}+\Pi_{K j}+\widehat{V_{K j}} \forall j \\
\sum_{j} \lambda_{P j} \widehat{q_{j}}+\sum_{j} \lambda_{P j} \widehat{c_{P j}}=\widehat{V_{P}}+\Pi_{P} \\
\sum_{j} \lambda_{N P j} \widehat{q_{j}}+\sum_{j} \lambda_{N P j} \widehat{c_{N P j}}=\widehat{V_{N P}}+\Pi_{N P}
\end{gathered}
$$

where $\Pi_{i}=\sum_{j} \lambda_{i j} \widehat{b_{i j}}$ represents the reduction in the use of factor $i$ across all sectors of produc- 
tion and $\lambda_{i j}$ denotes the fraction of factor $i$ employed in sector $j$. Following Jones [14], we refer to $\Pi_{i}$ as factor-specific technological change and to $\Pi_{j}$ in equation(2.9) as sector-specific technological change or, alternatively, as total factor productivity (TFP). Note that both these terms measure technological change at constant factor prices. Replacing $\widehat{q_{j}}$ in equations $(2.12)$ and $(2.13)$ with (2.11) we get:

$$
\begin{gathered}
\sum_{j} \lambda_{P j} \widehat{c_{P j}}-\sum_{j} \lambda_{P j} \widehat{c_{K j}}+\sum_{j} \lambda_{P j}\left(\widehat{V_{K j}}+\Pi_{K j}\right)=\widehat{V_{P}}+\Pi_{P} \\
\sum_{j} \lambda_{N P j} \widehat{c_{N P j}}-\sum_{j} \lambda_{N P j} \widehat{c_{K j}}+\sum_{j} \lambda_{N P j}\left(\widehat{V_{K j}}+\Pi_{K j}\right)=\widehat{V_{N P}}+\Pi_{N P}
\end{gathered}
$$

From equations (2.5)-(2.7) we get:

$$
\begin{gathered}
\widehat{c_{K j}}=E_{K j}^{K} \widehat{r_{j}}+E_{K j}^{P} \widehat{w_{P}}+E_{K j}^{N P \widehat{w_{N P}}} \forall j \\
\widehat{c_{P j}}=E_{P j}^{K} \widehat{r_{j}}+E_{P j}^{P} \widehat{w_{P}}+E_{P j}^{N P \widehat{w_{N P}}} \forall j \\
\widehat{c_{N P j}}=E_{N P j}^{K} \widehat{r_{j}}+E_{N P j}^{P} \widehat{w_{N P}}+E_{N P j}^{N P} \widehat{w_{N P}} \forall j
\end{gathered}
$$

where $E_{i j}^{k}=\left(\frac{\partial c_{i j}}{\partial w_{k}}\right)\left(\frac{w_{k}}{c_{i j}}\right)$ for $k=K, P, N P$ is defined, following Jones and Easton [15], as the elasticity of $c_{i j}$ with respect to changes in $w_{k}$, holding all other factor prices constant. Note that due to the zero-homogeneity of $c_{i j}, \sum_{k} E_{i j}^{k}=0 \forall i \forall j$ and $\sum_{i} \theta_{i j} E_{i j}^{k}=0 \forall k, j$. Further, by symmetry, $E_{i j}^{k}=\frac{\theta_{k j}}{\theta_{i j}} E_{k j}^{i} \forall i, j$

To solve this model for mobile factor prices, substitute equations $(2.16),(2.17)$ and $(2.18)$ in equations (2.14) and (2.15). This yields:

$$
\begin{gathered}
\sum_{j} \lambda_{P j} \varepsilon_{K j} \widehat{r_{j}}+\widehat{w_{P}} \sum_{j} \lambda_{P j} \varepsilon_{P j}+\widehat{w_{N P}} \sum_{j} \lambda_{P j} \varepsilon_{N P j}=\widehat{V_{P}^{*}}-\sum_{j} \lambda_{P j} \widehat{V_{K j}^{*}} \\
\sum_{j} \lambda_{N P j} \eta_{K j} \widehat{r_{j}}+\widehat{w_{P}} \sum_{j} \lambda_{N P j} \eta_{P j}+\widehat{w_{N P}} \sum_{j} \lambda_{N P j} \eta_{N P j}=\widehat{V_{N P}^{*}}-\sum_{j} \lambda_{N P j} \widehat{V_{K j}^{*}}
\end{gathered}
$$

where $\widehat{V_{i}^{*}}=\widehat{V}_{i}+\Pi_{i}, \varepsilon_{i j}=E_{P j}^{i}-E_{K j}^{i}$ and $\eta_{i j}=E_{N P j}^{i}-E_{K j}^{i}$. Therefore, $\varepsilon_{i j}\left(\eta_{i j}\right)$ measures the effect of a rise in the return to factor $i$ on the production-labor (non-production-labor) to 
capital ratio. We make the standard assumptions about own and cross-price elasticities such that $\varepsilon_{K j} \geqq 0, \varepsilon_{P j} \leqslant 0, \varepsilon_{N P j} \geqq 0, \eta_{K j} \geqq 0, \eta_{P j} \geqq 0$, and $\eta_{N P j} \leqslant 0$. From equation (2.9) we have:

$$
\widehat{r_{j}}=\frac{1}{\theta_{K j}}\left(\widehat{p_{j}}+\Pi_{j}-\theta_{P j} \widehat{w_{P}}-\theta_{N P j} \widehat{w_{N P}}\right) \forall j
$$

Using (2.21) in equations (2.19) and (2.20) yields

$$
\begin{gathered}
\sum_{j} \lambda_{P j} \frac{\varepsilon_{K j}}{\theta_{K j}}\left(\widehat{p_{j}}+\Pi_{j}\right)+\widehat{w_{P}}\left(\sum_{j} \lambda_{P j} \varepsilon_{P j}-\sum_{j} \lambda_{P j} \frac{\varepsilon_{K j}}{\theta_{K j}} \theta_{P j}\right) \\
+\widehat{w_{N P}}\left(\sum_{j} \lambda_{P j} \varepsilon_{N P j}-\sum_{j} \lambda_{P j} \frac{\varepsilon_{K j}}{\theta_{K j}} \theta_{N P j}\right)=\widehat{V_{P}^{*}}-\sum_{j} \lambda_{P j} \widehat{V_{K j}^{*}} \\
\sum_{j} \lambda_{N P j} \frac{\eta_{K j}}{\theta_{K j}}\left(\widehat{p_{j}}+\Pi_{j}\right)+\widehat{w_{P}}\left(\sum_{j} \lambda_{N P j} \eta_{P j}-\sum_{j} \lambda_{N P j} \frac{\eta_{K j}}{\theta_{K j}} \theta_{P j}\right) \\
+\widehat{w_{N P}}\left(\sum_{j} \lambda_{N P j} \eta_{N P j}-\sum_{j} \lambda_{N P j} \frac{\eta_{K j}}{\theta_{K j}} \theta_{N P j}\right)=\widehat{V_{N P}^{*}}-\sum_{j} \lambda_{N P j} \widehat{V_{K j}^{*}}
\end{gathered}
$$

which can be simplified to:

$$
\begin{aligned}
& {\left[\begin{array}{cc}
\sum_{j} \lambda_{P j} \theta_{P j} A_{j} & \sum_{j} \lambda_{P j} \theta_{N P j} B_{j} \\
\sum_{j} \lambda_{N P j} \theta_{P j} C_{j} & \sum_{j} \lambda_{N P j} \theta_{N P j} D_{j}
\end{array}\right]\left[\begin{array}{c}
\widehat{w_{P}} \\
\widehat{w_{N P}}
\end{array}\right] } \\
= & {\left[\begin{array}{l}
\sum_{j} \lambda_{P j} \frac{\varepsilon_{K j}}{\theta_{K j}}\left(\widehat{p_{j}}+\Pi_{j}\right)-\widehat{V_{P}^{*}}+\sum_{j} \lambda_{P j} \widehat{V_{K j}^{*}} \\
\sum_{j} \lambda_{N P j} \frac{\eta \eta_{K j}}{\theta_{K j}}\left(\widehat{p_{j}}+\Pi_{j}\right)-\widehat{V_{N P}^{*}}+\sum_{j} \lambda_{N P j} \widehat{V_{K j}^{*}}
\end{array}\right] }
\end{aligned}
$$

where $A_{j}=\left(\frac{\varepsilon_{K j}}{\theta_{K j}}-\frac{\varepsilon_{P j}}{\theta_{P j}}\right), B_{j}=\left(\frac{\varepsilon_{K j}}{\theta_{K j}}-\frac{\varepsilon_{N P j}}{\theta_{N P j}}\right), C_{j}=\left(\frac{\eta_{K j}}{\theta_{K j}}-\frac{\eta_{P j}}{\theta_{P j}}\right), D_{j}=\left(\frac{\eta_{K j}}{\theta_{K j}}-\frac{\eta_{N P j}}{\theta_{N P j}}\right)$. Solving equation (2.24) for $\widehat{w_{P}}$ and $\widehat{w_{N P}}$ yields:

$$
\begin{aligned}
\widehat{w_{P}}= & \frac{1}{\Delta}\left[\left\{\sum_{j} \lambda_{P j} \frac{\varepsilon_{K j}}{\theta_{K j}}\left(\widehat{p_{j}}+\Pi_{j}\right)-\widehat{V_{P}^{*}}+\sum_{j} \lambda_{P j} \widehat{V_{K j}^{*}}\right\}\left(\sum_{j} \lambda_{N P j} \theta_{N P j} D_{j}\right)-\right. \\
& \left.\left\{\sum_{j} \lambda_{N P j} \frac{\eta_{K j}}{\theta_{K j}}\left(\widehat{p_{j}}+\Pi_{j}\right)-\widehat{V_{N P}^{*}}+\sum_{j} \lambda_{N P j} \widehat{V_{K j}^{*}}\right\}\left(\sum_{j} \lambda_{P j} \theta_{N P j} B_{j}\right)\right] \\
\widehat{w_{N P}}= & \frac{1}{\Delta}\left[\left\{\sum_{j} \lambda_{N P j} \frac{\eta_{K j}}{\theta_{K j}}\left(\widehat{p_{j}}+\Pi_{j}\right)-\widehat{V_{N P}^{*}}+\sum_{j} \lambda_{N P j} \widehat{V_{K j}^{*}}\right\}\left(\sum_{j} \lambda_{P j} \theta_{P j} A_{j}\right)-\right. \\
& \left.\left\{\sum_{j} \lambda_{P j} \frac{\varepsilon_{K j}}{\theta_{K j}}\left(\widehat{p_{j}}+\Pi_{j}\right)-\widehat{V_{P}^{*}}+\sum_{j} \lambda_{P j} \widehat{V_{K j}^{*}}\right\}\left(\sum_{j} \lambda_{N P j} \theta_{P j} C_{j}\right)\right]
\end{aligned}
$$

where $\Delta=\left(\sum_{j} \lambda_{P j} \theta_{P j} A_{j}\right)\left(\sum_{j} \lambda_{N P j} \theta_{N P j} D_{j}\right)-\left(\sum_{j} \lambda_{P j} \theta_{N P j} B_{j}\right)\left(\sum_{j} \lambda_{N P j} \theta_{P j} C_{j}\right)$ which is positive under plausible conditions. The solutions from (2.25) and (2.26) can then be used to solve for 
$\widehat{r_{j}}$ using (2.21).

Equations (2.25) and (2.26) confirm what was noted in the previous section: changes in factor prices are functions of sectoral price changes, changes in labor and capital endowments, and both factor- and sector-specific technological change. In addition, changes in the skill premium depend on sectoral factor intensities $(\lambda)$ and sectoral differences in factor demand elasticities $(\varepsilon, \eta)$. Unfortunately, it is not possible, in general, to determine the sign of the partial derivatives of the skill premium $\left(\widehat{w_{N P}}-\widehat{w_{P}}\right)$ with respect to changes in product prices, endowments, and technological change $^{9}$. However, under certain, plausible conditions regarding factor intensities and elasticities (see Table 1), we find that the skill premium increases with the supply of production workers and/or production labor specific technical change. Likewise, the skill premium decreases with the supply of non-production workers and/or non-production labor specific technical change.

Table 1: Comparative Statics

\begin{tabular}{||l|c|c|c|c||}
\hline \hline & $\widehat{V_{N P}}$ & $\widehat{V_{P}}$ & $\Pi_{N P}$ & $\Pi_{P}$ \\
\hline$\widehat{w_{N P}}-\widehat{w_{P}}$ & $-{ }^{1}$ & $+^{2}$ & $-{ }^{1}$ & $+^{2}$ \\
\hline \hline
\end{tabular}

${ }^{1}$ if $\sum_{j} \lambda_{P j} \varepsilon_{K j}-\sum_{j} \frac{\varepsilon_{K j}}{\theta_{K j}}-\sum_{j} \varepsilon_{K j} \geqq 0$

$2_{\text {if }} \sum_{j} \frac{\eta_{K j}}{\theta_{K j}}-\sum_{j} \eta_{K j}+\sum_{j} \lambda_{N P j} \eta_{K j} \geqq 0$

\section{Data}

To obtain quantitative results for the equilibrium factor price changes, we first write out the full system of equilibrium equations as given in (2.9), (2.19) and (2.20) in matrix format:

\footnotetext{
${ }^{9}$ The ambiguity of the change in the skill premium with regard to changes in output prices is a result that can also be found in Burgess [5] who investigates a SF model with intermediate inputs and in Thompson [?] who analyzes a SF model with two shared inputs similar to ours.
} 


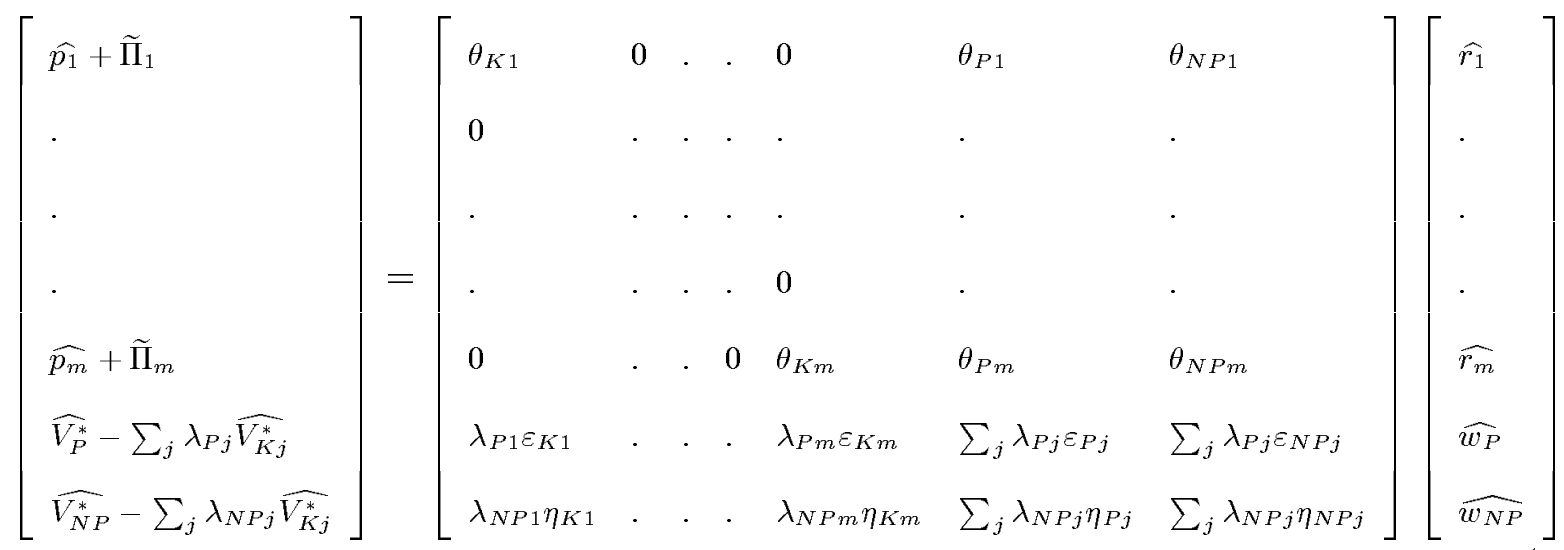

To calculate equilibrium factor price changes, we use data from the NBER-CES Manufacturing Database from 1958 to 1992 [1]. This database contains annual information for 448 U.S. manufacturing industries at the 4-digit 1972 SIC. Due to missing data, we exclude SIC 2384, 2794 and 3292 from our analysis. We define the growth rate in period $t$ as the change between period $t+1$ and $t$ relative to period $t$ (see Leamer [22] for a similar definition). Growth rates are thus forward looking. As a result, we lose observations for 1992. The $\varepsilon$ and $\eta$ variables in the matrix above are functions of factor-demand elasticities. These elasticities are not directly observed and must be estimated. A detailed description of how we estimate these elasticities is given in Appendix A. Appendix B contains a brief description of how we construct the remaining variables as well as descriptive statistics for the key exogenous variables (Table 2).

A number of data issues related to the construction of the exogenous variables need to be discussed at this point. First, we use the production and non-production labor classification from the NBER data set as a proxy for unskilled and skilled workers. This approximation has been criticized on the grounds that production worker category may include workers with high education levels or skills, while the group of non-production workers may include workers with low education levels or skills. However, we maintain this classification since it is a reasonable approximation 
used widely in the literature. In addition, results by Kahn and Lim [16] show a high correlation between cost-shares based on the two classification schemes indicating that the two schemes are close substitutes. Second, due to the lack of (manufacturing) sector specific data on changes in factor endowments, we use growth rates of labor employment and capital stock instead. The error caused by this approximation will be small if there is sufficient co-movement between endowments and actual factor utilization per industry. Kosters [18] (Table 1-6) presents estimates for changes in the proportion of the work force from 1973-88 for workers with 12 years of education or less, and for workers with 16 or more years of education. Translated into annual growth rates, his estimates show that the endowment of unskilled and skilled workers grew at a rate of -.0076 and .0048 , respectively. The corresponding growth rates for unskilled and skilled workers using average manufacturing employment data are -.0078 and .0104, respectively. Third, as in Feenstra and Hanson [9], capital factor shares are computed as 1 minus labor and materials factor shares , i.e., as a residual ${ }^{10}$. Fourth, our theoretical model does not include intermediate inputs. In the empirical analysis, we account for the impact of intermediate inputs on product prices by deriving a value-added price change measure. This is done, as in Leamer [22], by subtracting from the vector of product price changes the inner product of a diagonal matrix with material cost-shares on its main diagonal and a vector of growth rates of material deflators. Fifth, using the estimated factordemand elasticities (see Appendix A), we derive an estimate of $\widehat{c_{i j}}$ using the following equations ${ }^{11}$ :

$$
\begin{gathered}
\overline{\widehat{c_{K j}}}=E_{K}^{K} \widehat{r_{j}}+E_{K}^{P \widehat{w_{P j}}}+E_{K}^{N P \widehat{w_{N P j}}} \forall j \\
\overline{\widehat{c_{P j}}}=E_{P}^{K} \widehat{r_{j}}+E_{P}^{P \widehat{w_{P j}}}+E_{P}^{N P \widehat{w_{N P j}}} \forall j \\
\overline{\widehat{c_{N P j}}}=E_{N P}^{K} \widehat{r_{j}}+E_{N P}^{P} \widehat{w_{N P j}}+E_{N P \widehat{w_{N P j}}}^{N P j}
\end{gathered}
$$

\footnotetext{
${ }^{10}$ Errors in the NBER dataset resulted in a negative rental price of capital for a few industries. These values were exogenously fixed at an uniform rate of $10 \%$.

${ }^{11}$ Note that there is a difference between (2.16)-(2.18) and (3.2)-(3.4). While the returns to the mobile factors are uniform across industries in the former set of equations, they are industry-specific in the latter. This adjustment is necessary to perform the estimation procedure described in Appendix A.
} 
where $\overline{\widehat{c_{i j}}}$ is the predicted value of $\widehat{c_{i j}}$. We use this estimate together with $(2.4)$ to derive a measure of $\widehat{b_{i j}}$. Finally, the assumption of perfect mobility of production and non-production labor across sectors conflicts with the observed variation of factor prices across sectors. To adjust for this empirical fact, we rewrite equation (2.9), following Feenstra and Hanson [9], as

$$
\widehat{p_{j}}=\theta_{K j} \widehat{r_{j}}+\theta_{P j} \widehat{w_{P}}+\theta_{N P j} \widehat{w_{N P}}-\widetilde{\Pi}_{j} \forall j
$$

where $\widetilde{\Pi}_{j}=\Pi_{j}-\theta_{P j}\left(\widehat{w_{P j}}-\widehat{w_{P}}\right)-\theta_{N P j}\left(\widehat{w_{N P j}}-\widehat{w_{N P}}\right)$. We will refer to $\widetilde{\Pi}_{j}$ as effective TFP. With these caveats in mind, we calculate the predicted skill premium growth rate as the difference between $\widehat{w_{N P}}$ and $\widehat{w_{P}}$ using (3.1), followed by a decomposition of the total effect into the changes caused by globalization, endowment, and technological change. To calculate the impact of a particular factor, say product price change, we set all other exogenous variables in the LHS vector of (3.1), i.e., $\widehat{V_{P}^{*}}-\sum_{j} \lambda_{P j} \widehat{V_{K j}^{*}}, \widehat{V_{N P}^{*}}-\sum_{j} \lambda_{N P j} \widehat{V_{K j}^{*}}, \widetilde{\Pi}_{j}$, to zero.

\section{Empirical Results}

Our main results are presented in Tables $3-6$. Table 3 contains the observed and predicted annual skill premium growth rates together with the decomposition of the predicted series by major components: trade, technology, capital and labor endowments. Based on the results in Table 3 we calculate a number of summary statistics, presented in Tables 4-6. The informational content of Table 3 is also presented in a series of graphs (see Figures 1-6). As Table 4 shows, the actual average annual growth rate of the skill premium from $1958-91$ is .12\% per year. We also report skill premium growth for three sub-periods: 1958-68, 1969-78, and 1979-91 which correspond to episodes with different trends in the skill premium. While there was modest skill premium growth of $.35 \%$ per year over the first sub-period, the skill premium actually declined by .30\% over the next decade. In the last sub-period, the skill premium again grew at an annual rate of $.25 \%$. Comparing the 
actual growth rates with the growth rates predicted by our model, we find that the model correctly predicts the direction of changes in the skill premium for the overall sample period as well as for two of the sub-periods. Only during 1969-78 the model predicts a very modest rise in the skill premium while the actual skill premium growth rate is negative.

In terms of the magnitude of the predicted change, the model overpredicts the average annual increase in the skill premium over the sample period $(.12 \%$ actual growth compared to $.81 \%$ predicted growth). While actual and predicted values are nearly identical for the 1958-68 period, the model overpredicts skill premium growth slightly for 1969-78 and more pointedly for 1979-91. In terms of standard deviations, predicted and actual values are very close during the first two subperiods indicating a good fit of the model in terms of volatility. In the last sub-period the volatility of the predicted values exceeds actual volatility. Table 4 also shows that the correlation between actual and predicted skill premium is reasonably high for all periods. The residual shares reveal that for the entire sample period, roughly $58 \%$ of the observed variation in the skill premium is explained by the model ${ }^{12}$. Similar results hold for the three sub-periods. Figure 1 depicts observed and predicted growth rates for each year. The graph clearly shows the strong co-movement between the two time series, especially during the earlier periods.

Table 5 contains the decomposition of the predicted skill premium growth rate. Trade effects working through product price changes had a positive effect on the skill premium, both for the entire sample period as well as for most sub-periods. Only during the 1958-68 period did changes in product prices lead to a decline in the predicted skill premium. Besides trade effects, changes in sector-specific capital endowments were the other significant driving force behind the increase in the skill premium. Just like changes in prices, changes in capital endowments had a rather small

\footnotetext{
${ }^{12}$ The residual share is defined as: $\frac{a b s(\text { actual-predicted })}{a b s(a c t u a l-p r e d i c t e d)+a b s(\text { predicted })}$. This give us the \% of actual growth rates that is unexplained.
} 
impact on the predicted skill premium during the first two sub-periods but a stronger effect during the last sub-period. Changes in labor endowments had a negative impact on the predicted skill premium for all sub-periods. This result can be easily understood if one considers the relative increase in the endowments with non-production workers vis-a-vis production workers in each subperiod documented in Table 2. The average annual growth rate of the skill endowment differential $\left(\widehat{V_{N P}}-\widehat{V_{P}}\right)$ is positive for the entire sample period $(.96 \%)$ as well as for each of the three sub-periods $(.24 \%, 1.35 \%$, and $1.26 \%$, respectively). Finally, technology increased the predicted skill premium for two of the three sub-periods. Over the entire sample period, the impact of technological change on the skill premium was positive as well though small in comparison to the effect of trade and capital endowment changes.

The actual skill premium growth rates and predicted changes by each of the four components are shown in Figures 2-5. These graphs show that the magnitude of skill premium changes caused by changes in output prices and capital endowments is less severe than those caused by changes in technology and labor endowments. This result can also be seen from Table 5 which contains relative contribution to the explained variation by each component ${ }^{13}$. Of these, price movements account for only $19 \%$ of the variation in the predicted skill premium over the sample period. Technology and labor endowment changes account for $27 \%$ and $39 \%$, respectively, while changes in the endowment with capital contribute only $15 \%$. These relative contributions vary little across sub-periods. However, while the variation accounted for by trade and capital endowment changes increases continuously over sub-periods, the opposite is true for the variability contributed by technology and labor endowment changes.

\footnotetext{
${ }^{13}$ The contribution by exogenous factor $i$ is defined as: $\frac{a b s\left(\text { predicted }_{i}\right)}{\sum a b s\left(\text { predicted }_{j}\right)}$.
} 


\section{Sensitivity Results}

The question arises how sensitive our findings are to changes in the calculation of the various exogenous variables presented in Table 2. Unfortunately, due to the lack of suitable alternative data sets covering a comparable number of industries and time periods, sensitivity tests of our results are difficult to perform. However, since the NBER-CES data set includes a variable that measures TFP, we replace our own TFP measure with this variable. The new results for predicted versus actual skill premium growth as well as the decomposition of the predicted values by component are given in Tables 6 and 7, respectively. As Table 6 shows, the use of the NBER measure of TFP does not change the predicted values in any major way with one exception. For the period 1969-78, predicted and actual values now have the same sign. While this difference may be considered an improvement, it has to be noticed that the correlation between actual and predicted values is now negative for this sub-period. In addition, the correlation coefficients for all sub-periods as well as for the overall sample period are now substantially lower than before. Further, the residual shares indicate that the model now explains less than $50 \%$ of the overall variation in the observed skill premium, a small but noticeable decline. Table 7 generates further evidence that our results are robust with regard to alternative TFP measures. As the decomposition values for the technology column indicate, neither signs nor magnitudes differ markedly from those in the corresponding column of Table 5.

\section{Summary and Conclusions}

This paper contributes to the trade and wage inequality literature in two ways. First, by choosing a specific-factor framework instead of the more frequently used H-O model, we use a theoretical model that allows a larger number of exogenous factors to affect relative wages. In addition to the effects of product price movements and TFP accounted for by the H-O model, the SF model allows 
for capital and labor endowment changes as well as factor-specific technological change to affect the skill premium. Second, applying the theoretical model to data for U.S. manufacturing industries, we are able to provide evidence on the relative contributions to changes in the skill premium for each exogenous component.

The paper has several important results. First, trade operating through product price changes had a positive impact on the skill premium, in particular during the later half of the sample. Second, increases in the supply of skilled workers relative to unskilled workers worked towards lowering the skill premium, while new investment in capital goods had a positive effect throughout the sample period. Finally, the combined impact of all technological change measures on the skill premium was positive, but moderate.

The analysis presented in this paper lends itself to several extensions. The SF framework presented here could be easily applied to data for other countries, just as 'mandated-wage regression' analysis of U.S. industries was later applied to investigate wage inequality issues in other countries such as the UK and Sweden. Given the shortcomings of the H-O/mandated wage regression method, it would be interesting to compare the results from these studies with the decomposition results from the SF framework. Another extension would be to include service sector industries in the empirical analysis. The services sector has witnessed significant SBTC over the last two decades, and the effect of this change in technology on the skill premium could be identified in our framework. Lastly, the SF framework could be used to account for globalization effects other than those working through product price changes. In particular, the model could be used to study the effects of increased international capital mobility on the skill premium. 


\section{Appendix A}

To calculate the predicted skill premium in equation (3.1), we need values for $\varepsilon_{i j}$ and $\eta_{i j}$. Since $\varepsilon_{i j}=E_{P j}^{i}-E_{K j}^{i}$ and $\eta_{i j}=E_{N P j}^{i}-E_{K j}^{i}$, we need to find values for $E_{i j}^{k}$. Since $\widehat{a_{i j}}=\widehat{V_{i j}}-\widehat{Q_{j}}$, we can use equations (2.4) and (2.16)-(2.18) to write the following:

$$
\widehat{V_{i j}}-\widehat{Q_{j}}=E_{K j}^{K} \widehat{r_{j}}+E_{K j}^{P} \widehat{w_{P}}+E_{K j}^{N P \widehat{w_{N P}}}-\widehat{b_{i j}} \forall i
$$

Moving the $\widehat{Q_{j}}$ term to the right, holding technology constant, i.e., $\widehat{b_{i j}}=0$, and indexing factor returns to labor by sector $j$,we get:

$$
\widehat{V_{i j}}=E_{K j}^{K} \widehat{r_{j}}+E_{K j}^{P} \widehat{w_{P j}}+E_{K j}^{N P \widehat{w_{N P j}}}+\widehat{Q_{j}} \forall i
$$

The $E_{i j}^{k}$ on the RHS of this equation are factor demand elasticities. Following the labor demand literature, summarized in Hamermesh [10], we estimate these elasticities with the following model ${ }^{14}$ :

$$
\ln V_{i j}=\sum_{i} \beta_{i} \ln w_{i}+\gamma_{j} \ln Q_{j}+\varrho_{j}
$$

where $\varrho_{j}$ is the error term. As noted in the literature (see Roberts and Skoufias [25]) equation (A.3.) must be estimated in long time-differences to avoid the potential errors-in-variables problem. Accordingly, we estimate (A.3.) using 10-year time differences. Using time-series data we estimate industry-specific factor demand elasticities in a SUR framework. According to our theoretical model we impose the following constraints: $\sum_{i} \beta_{i}=0$ (homogeneity), $\gamma_{j}=1$, and $E_{i j}^{k}=\frac{\theta_{k j}}{\theta_{i j}} E_{k j}^{i}$ $\forall i, j$ (cross-equation symmetry). The industry averaged estimates of the nine demand elasticities are given in Table A1. As expected, all own price elasticities are negative and lie within the range reported in Hamermesh [-.15, -.75].

\footnotetext{
${ }^{14}$ Slaughter [28] uses a similar approach to estimate factor demand elasticities for industry groups.
} 


\section{Table A1: Factor Demand Elasticities}

$$
\begin{gathered}
\text { (Average across industries) } \\
{\left[\begin{array}{lll}
E_{K}^{K} & E_{P}^{K} & E_{N P}^{K} \\
E_{K}^{P} & E_{P}^{P} & E_{N P}^{P} \\
E_{K}^{N P} & E_{P}^{N P} & E_{N P}^{N P}
\end{array}\right]=\left[\begin{array}{ccc}
-.33 & .39 & .34 \\
.23 & -.43 & .12 \\
.10 & .32 & -.45
\end{array}\right]}
\end{gathered}
$$

\section{Appendix B}

Here we describe the construction of the variables used in our analysis. All growth rates are annual growth rates. Variable names in capital letters denote NBER-CES data set variables, a detailed description of which can be found in the NBER documentation [1]. Industries are indexed by $j$.

$V_{N P j}:$ Non-production employment in $j t h$ industry $=\mathrm{EMP}_{j}-\mathrm{PRODE}_{j}$ $w_{N P}(\text { actual })_{j}:$ Non-production labor wage rate in $j$ th industry $=\left(\mathrm{PAY}_{j}-\mathrm{PRODW}_{j}\right) / V_{N P j}$

$r_{j}:$ User cost of capital for $j$ th industry $=($ VADD-PAY $) / \mathrm{CAP}$

$V_{P}:$ Total production employment $=\sum_{j} \mathrm{PRODE}_{j}$

$V_{N P}:$ Total non-production employment $=\sum_{j} V_{N P j}$

$V_{K j}:$ Total capital stock $=\mathrm{CAP}_{j}$

$\widehat{V_{P}}:$ Growth rate of total production employment $=$ growth rate of $V_{P}$

$\widehat{V_{N P}}:$ Growth rate of total non-production employment $=$ growth rate of $V_{N P}$

$\widehat{V_{K j}}:$ Growth rate of total capital stock $=$ growth rate of $V_{K j}$

$\lambda_{P j}:$ Share of $j$ th industry in total production labor force $=\mathrm{PRODE} / V_{P}$

$\lambda_{N P j}:$ Share of $j t h$ industry in total non-production labor force $=V_{N P j} / V_{N P}$

$\lambda_{K j}$ : equals 1 by as capital is a specific factor 
$\theta_{P j}:$ Revenue share of production labor for $j t h$ industry $=$ PRODW $/ V S H I P_{j}$

$\theta_{N P j}:$ Revenue share of non-production labor for $j t h$ industry $=w_{N P} / V S H I P_{j}$

$\theta_{K j}=1-\theta_{P j}-\theta_{N P j}-\theta_{M j}$

$\theta_{M j}:$ Materials revenue-share for $j t h$ industry $=\operatorname{MATCOST} / V S H I P_{j}$

$\widehat{Q_{j}}:$ Growth rate of real value added

$\widehat{a_{P j}}$ : growth rate of production labor-input coefficient for industry $j=\left(P \widehat{R O D} E_{j}\right)-\widehat{Q_{j}}$

$\widehat{a_{N P j}}:$ growth rate of non-production labor-input coefficient for industry $j=\left(\widehat{V_{N P j}}\right)-\widehat{Q_{j}}$

$\widehat{a_{K j}}$ : growth rate of capital-input coefficient for industry $j=\left(\widehat{C A P_{j}}\right)-\widehat{Q_{j}}$

$\Pi_{j}$ : Total factor productivity growth in $j$ th industry $=\sum_{i} \Theta_{i j} \widehat{b_{i j}}$.

$\Pi_{i}$ : Measure of factor-specific technological change for $i$-th factor $=\sum_{j} \lambda_{i j} \widehat{b_{i j}}$

$\widehat{p_{M} j}:$ growth rate of PIMAT for industry $j$

$\mu_{j} \widehat{p}$ : adjustment term for intermediate inputs $=$ product of an $m \times m$ matrix with materials revenue-share $\theta_{M j}$ on its main diagonal with the $m \mathrm{x} 1$ vector of $\widehat{p_{M} j}$ 
Table 2: Descriptive Statistics

\begin{tabular}{|c|c|c|c|c|c|c|c|c|c|c|c|}
\hline Variable & Year & Mean & S.D. & Min & $\operatorname{Max}$ & Variable & Year & Mean & S.D. & Min & $\operatorname{Max}$ \\
\hline \multirow[t]{4}{*}{$\widehat{p}_{j}$} & 1958-91 & .0390 & .0729 & -.4220 & 1.8696 & $\Pi_{P}$ & 1958-91 & .0287 & .0514 & -.0987 & .1140 \\
\hline & $1958-68$ & .0135 & .0383 & -.2286 & .2813 & & $1958-68$ & .0392 & .0397 & -.0136 & .1131 \\
\hline & 1969-78 & .0734 & .0996 & -.4220 & 1.8696 & & $1969-78$ & .0179 & .0605 & -.0987 & .1077 \\
\hline & 1979-91 & .0341 & .0595 & -.3986 & .9710 & & 1979-91 & .0280 & .0548 & -.0585 & .1140 \\
\hline \multirow[t]{4}{*}{$\tilde{\Pi}_{j}$} & 1958-91 & .0083 & .0674 & -.3473 & 2.5477 & $\Pi_{N P}$ & 1958-91 & .0220 & .0624 & -.1300 & .1134 \\
\hline & $1958-68$ & .0137 & .0539 & -.3468 & .5402 & & $1958-68$ & .0317 & .0501 & -.0497 & .0978 \\
\hline & 1969-78 & .0018 & .0675 & -.2995 & .8045 & & $1969-78$ & .0194 & .0822 & -.1300 & .1134 \\
\hline & 1979-91 & .0088 & .0767 & -.3473 & 2.5477 & & 1979-91 & .0159 & .0585 & -.0811 & .1079 \\
\hline \multirow[t]{4}{*}{$\widehat{V_{P}}$} & 1958-91 & .0003 & .0410 & -.1002 & .0575 & $\Pi_{K j}$ & 1958-91 & .0015 & .1571 & -5.6512 & 9.4348 \\
\hline & $1958-68$ & .0184 & .0278 & -.0336 & .0575 & & $1958-68$ & .0106 & .1063 & -.8433 & 1.1159 \\
\hline & 1969-78 & -.0023 & .0531 & -.1002 & .0517 & & $1969-78$ & -.0147 & .1397 & -1.6152 & 1.0124 \\
\hline & 1979-91 & -.0139 & .0351 & -.0838 & .0408 & & 1979-91 & .0063 & .1993 & -5.6512 & 9.4348 \\
\hline \multirow[t]{4}{*}{$\widehat{V_{N P}}$} & 1958-91 & .0099 & .0240 & -.0422 & .0488 & $\widehat{V_{K j}}$ & 1958-91 & .0302 & .0531 & -.1494 & .9359 \\
\hline & $1958-68$ & .0208 & .0194 & -.0229 & .0488 & & $1958-68$ & .0493 & .0651 & -.1447 & .9359 \\
\hline & 1969-78 & .0112 & .0305 & -.0422 & .0422 & & $1969-78$ & .0345 & .0466 & -.1494 & .5071 \\
\hline & $1979-91$ & -.0013 & .0169 & -.0316 & .0287 & & 1979-91 & .0106 & .0376 & -.1447 & .3955 \\
\hline
\end{tabular}




\section{References}

[1] Bartelsman, E.J. and W. Gray, 1996, NBER Manufacturing Productivity Database, NBER Technical Working Paper No.205

[2] Baldwin, R.E. and G.G. Cain, 1997, Shifts in U.S. Relative Wages: The Role of Trade, Technology and Factor Endowments, NBER Working Paper No. 5934.

[3] Berman, E., J. Bound and Z. Griliches, 1994, Changes in the Demand for Skilled Labor within U.S. Manufacturing: Evidence from the Annual Survey of Manufactures, Quarterly Journal of Economics 109(2), 367-397.

[4] Berman, E., J. Bound and S. Machin, 1998, Implications of Skill-Biased Technological Change: International Evidence, Quarterly Journal of Economics 113(4), 1245-1280.

[5] Burgess, D.F., 1980, Protection, Real Wages, and the Neoclassical Ambiguity with Interindustry Flows, Journal of Political Economy 88 (4), 783-802.

[6] Cline, W.R., 1997, Trade and Income Distribution, Institute for International Economics, Washington D.C.

[7] Dasgupta, I., and T. Osang, 2000, Globalization and Relative Wages: Further Evidence from U.S. Manufacturing Industries, International Review of Economics and Finance, forthcoming.

[8] Engerman, S.L. and R.W. Jones, 1996, Trade, Technology and Wages: A Tale of Two Countries, AEA Papers and Proceedings, 35-40.

[9] Feenstra, R.C. and G.H. Hanson, 1999, The Impact of Outsourcing and High-Technology Capital On Wages: Estimates for the United States, 1979-1990, Quarterly Journal of Economics $114(3), 907-40$. 
[10] Hamermesh, D.S., 1993, Labor Demand, Princeton University Press.

[11] Haskel, J. and M.J. Slaughter, 2001, Trade, Technology and U.K. Wage Inequality, The Economic Journal 110, 1-27.

[12] Jones, R.W., 1971, A Three Factor Model in Theory, Trade and History, in J.Bhagwati et. al. (eds.), Trade, Balance of Payments and Growth, 3-21, Amsterdam: North-Holland.

[13] Jones, R.W., 1975, Income Distribution and Effective Protection in an Multicommodity Trade Model, Journal of Economic Theory 11, 1-15.

[14] Jones, R.W., 1996, International Trade, Real Wages, and Technical progress: The SpecificFactors Model, International Review of Economics and Finance 5(2), 1-15.

[15] Jones, R.W. and S.T. Easton, 1983, Factor Intensities and Factor Substitution in General Equilibrium, Journal of International Economics 15, 65-99.

[16] Kahn, J.A. and J. Lim, 1998, Skilled Labor-Augmenting Technical Progress in U.S. Manufacturing, Quarterly Journal of Economics 113(4), 1281-1308.

[17] Kohli, U., 1993, U.S. Technology and the Specific-Factors Model, Journal of International Economics 34, 115-136.

[18] Kosters, M., 1991, Wages and Demographics, in Kosters ed. Workers and Their Wages: Changing Patterns in the United States, American Enterprise Institute, Washington D.C.

[19] Krueger, A.B., 1993, How computers changed the wage structure: Evidence from microdata, 1984-1989, Quarterly Journal of Economics 108, 33-60.

[20] Krueger, A.B., 1997, Labor Market Shifts and the Price Puzzle Revisited, NBER Working Paper No. 5924. 
[21] Lawrence, R.Z., and M.J. Slaughter, 1993, International Trade and American Wages in the 1980's: Giant Sucking Sound or Small Hiccup?, Brookings Papers on Economic Activity: Microeconomics 2:1993, 161-210.

[22] Leamer, E.E., 1998, In Search of Stolper-Samuelson Linkages between International Trade and Lower Wages, in: S.M.Collins, ed., Imports, Exports and the American Worker (Brookings Institution, Washington, DC), 141-203.

[23] Magee, S.P., 1980, Three Simple Tests of the Stolper-Samuelson Theorem , in Peter Oppenheimer (ed.), Issues in International Economics, London, Oriel Press, 138-153.

[24] Magee, S.P., K. Yoo, and N. Choi, 1999, The United States is a Small Country in World Trade, mimeo, University of Texas at Austin.

[25] Roberts, M.J. and E. Skoufias, 1997, The Long-Run Demand for Skilled and Unskilled Workers in Colombian Manufacturing Plants, Review of Economics and Statistics 79(2), 330-334.

[26] Sachs, J.D. and H.J. Shatz, 1994, Trade and Jobs in U.S. Manufacturing, Brookings Papers on Economic Activity 1:1994, 1-84.

[27] Slaughter, M.J., 2000, What Are The Results of Product-Price Studies and What Can We Learn From Their Differences?, in R.C. Feenstra (ed), The Impact of International Trade on Wages, National Bureau of Economic Research, Conference Volume, 129-170.

[28] Slaughter, M.J., 1997, International Trade and Labor Demand Elasticities, NBER Working Paper No. 6262.

[29] Thompson, H., 1989, Do tariffs protect specific factors?, Canadian Journal of Economics 22 (2), 406-12. 


\begin{tabular}{|c|c|c|c|c|c|c|}
\hline \multicolumn{7}{|c|}{ Table 3: Observed and Predicted Annual Skill Premium Growth Rates } \\
\hline Year & Observed & Predicted & Trade & Technology & $\begin{array}{c}\text { Labor } \\
\text { endowments }\end{array}$ & $\begin{array}{c}\text { Capital } \\
\text { endowments }\end{array}$ \\
\hline 1958 & 0.0397 & 0.0429 & -0.0049 & -0.0257 & 0.0659 & 0.0076 \\
\hline 1959 & 0.0016 & 0.0110 & 0.0126 & 0.0455 & -0.0593 & 0.0122 \\
\hline 1960 & 0.0053 & -0.0045 & 0.0008 & 0.0501 & -0.0656 & 0.0102 \\
\hline 1961 & -0.0074 & -0.0159 & 0.0004 & -0.0393 & 0.0147 & 0.0083 \\
\hline 1962 & -0.0375 & -0.0270 & -0.0190 & -0.0409 & 0.0327 & 0.0002 \\
\hline 1963 & 0.0045 & 0.0034 & 0.0023 & 0.0040 & -0.0067 & 0.0038 \\
\hline 1964 & 0.0157 & 0.0270 & -0.0051 & -0.0088 & 0.0453 & -0.0045 \\
\hline 1965 & 0.0120 & 0.0052 & -0.0091 & 0.0030 & 0.0091 & 0.0022 \\
\hline 1966 & 0.0133 & 0.0102 & 0.0209 & 0.0258 & -0.0465 & 0.0099 \\
\hline 1967 & -0.0058 & -0.0196 & -0.0093 & 0.0090 & -0.0257 & 0.0065 \\
\hline 1968 & -0.0030 & 0.0070 & 0.0033 & 0.0204 & -0.0199 & 0.0032 \\
\hline 1969 & -0.0194 & -0.0197 & 0.0238 & 0.0244 & -0.0701 & 0.0022 \\
\hline 1970 & -0.0069 & 0.0043 & 0.0091 & -0.0003 & -0.0048 & 0.0003 \\
\hline 1971 & 0.0107 & -0.0086 & -0.0186 & -0.0688 & 0.0868 & -0.0080 \\
\hline 1972 & 0.0050 & 0.0065 & -0.0144 & -0.0029 & 0.0269 & -0.0032 \\
\hline 1973 & -0.0077 & -0.0063 & -0.0389 & 0.0925 & -0.0612 & 0.0012 \\
\hline 1974 & 0.0054 & 0.0121 & 0.0453 & 0.0697 & -0.1058 & 0.0029 \\
\hline 1975 & -0.0091 & 0.0061 & 0.0138 & -0.0621 & 0.0509 & 0.0035 \\
\hline 1976 & -0.0068 & 0.0019 & 0.0041 & -0.0123 & 0.0031 & 0.0070 \\
\hline 1977 & 0.0068 & 0.0085 & 0.0012 & 0.0025 & -0.0059 & 0.0107 \\
\hline 1978 & -0.0076 & 0.0014 & -0.0027 & 0.0242 & -0.0391 & 0.0189 \\
\hline 1979 & -0.0054 & 0.0130 & 0.0370 & 0.0963 & -0.1431 & 0.0229 \\
\hline 1980 & -0.0044 & 0.0110 & 0.0259 & -0.0076 & -0.0326 & 0.0254 \\
\hline 1981 & -0.0270 & -0.0104 & 0.0444 & 0.0758 & -0.1606 & 0.0300 \\
\hline 1982 & 0.0196 & 0.0173 & 0.0547 & -0.0959 & 0.0308 & 0.0277 \\
\hline 1983 & 0.0144 & 0.0399 & 0.0353 & -0.0754 & 0.0447 & 0.0353 \\
\hline 1984 & -0.0085 & 0.0164 & 0.0281 & 0.0253 & -0.0755 & 0.0385 \\
\hline 1985 & -0.0021 & -0.0158 & 0.0156 & -0.0049 & -0.0571 & 0.0307 \\
\hline 1986 & 0.0000 & 0.0627 & 0.0099 & 0.0087 & 0.0170 & 0.0270 \\
\hline 1987 & 0.0132 & 0.0090 & 0.0043 & -0.0255 & 0.0098 & 0.0204 \\
\hline 1988 & 0.0217 & 0.0356 & 0.0165 & -0.0148 & 0.0124 & 0.0216 \\
\hline 1989 & 0.0054 & 0.0141 & 0.0296 & -0.0011 & -0.0308 & 0.0166 \\
\hline 1990 & -0.0031 & 0.0258 & 0.0396 & 0.0029 & -0.0308 & 0.0142 \\
\hline 1991 & 0.0084 & 0.0096 & 0.0195 & -0.0287 & 0.0067 & 0.0121 \\
\hline
\end{tabular}




\begin{tabular}{|cccccc|}
\hline \multicolumn{2}{|c|}{ Table 4: Observed and Predicted Average Annual Skill Premium } \\
Growth Rate \\
Years & & \multicolumn{5}{c|}{ Observed } & Predicted & Correlations & Residual Shares (\%) \\
& & & & & \\
$1958-91$ & Mean & 0.0012 & 0.0081 & 0.56 & 42.31 \\
& (S.D.) & 0.0143 & 0.0190 & & \\
$1958-68$ & Mean & 0.0035 & 0.0036 & 0.89 & 38.04 \\
& (S.D.) & 0.0189 & 0.0203 & & \\
$1969-78$ & Mean & -0.0030 & 0.0006 & 0.50 & 47.21 \\
& (S.D.) & 0.0094 & 0.0095 & & \\
$1979-91$ & Mean & 0.0025 & 0.0176 & 0.42 & 42.14 \\
& (S.D.) & 0.0133 & 0.0205 & & \\
\hline
\end{tabular}

Table 5: Decomposition of the predicted skill-premium growth rate

\begin{tabular}{|c|c|c|c|c|}
\hline Years & Trade & Technology & $\begin{array}{c}\text { Labor } \\
\text { Endowments }\end{array}$ & $\begin{array}{c}\text { Capital } \\
\text { Endowments }\end{array}$ \\
\hline 1958-91 & 0.0111 & 0.0019 & -0.0172 & 0.0123 \\
\hline $1958-68$ & -0.0006 & 0.0039 & -0.0051 & 0.0054 \\
\hline 1969-78 & 0.0023 & 0.0067 & -0.0119 & 0.0036 \\
\hline $1979-91$ & 0.0277 & -0.0035 & -0.0315 & 0.0248 \\
\hline
\end{tabular}




\begin{tabular}{|cccccc|}
\hline \multicolumn{5}{|c}{ Table 6: Observed and Predicted Average Annual Skill Premium } \\
Growth Rate (NBER TFP measure) & \\
Years & & Observed & Predicted & Correlations & Residual Shares (\%) \\
& & & & & \\
$1958-91$ & Mean & 0.0012 & 0.0074 & 0.19 & 54.69 \\
& (S.D.) & 0.0143 & 0.0252 & & \\
$1958-68$ & Mean & 0.0035 & 0.0053 & 0.18 & 46.71 \\
& (S.D.) & 0.0189 & 0.0293 & & \\
$1969-78$ & Mean & -0.0030 & -0.0021 & -0.49 & 58.68 \\
& (S.D.) & 0.0094 & 0.0186 & & \\
$1979-91$ & Mean & 0.0025 & 0.0166 & 0.32 & \\
& (S.D.) & 0.0133 & 0.0246 & & \\
\hline
\end{tabular}

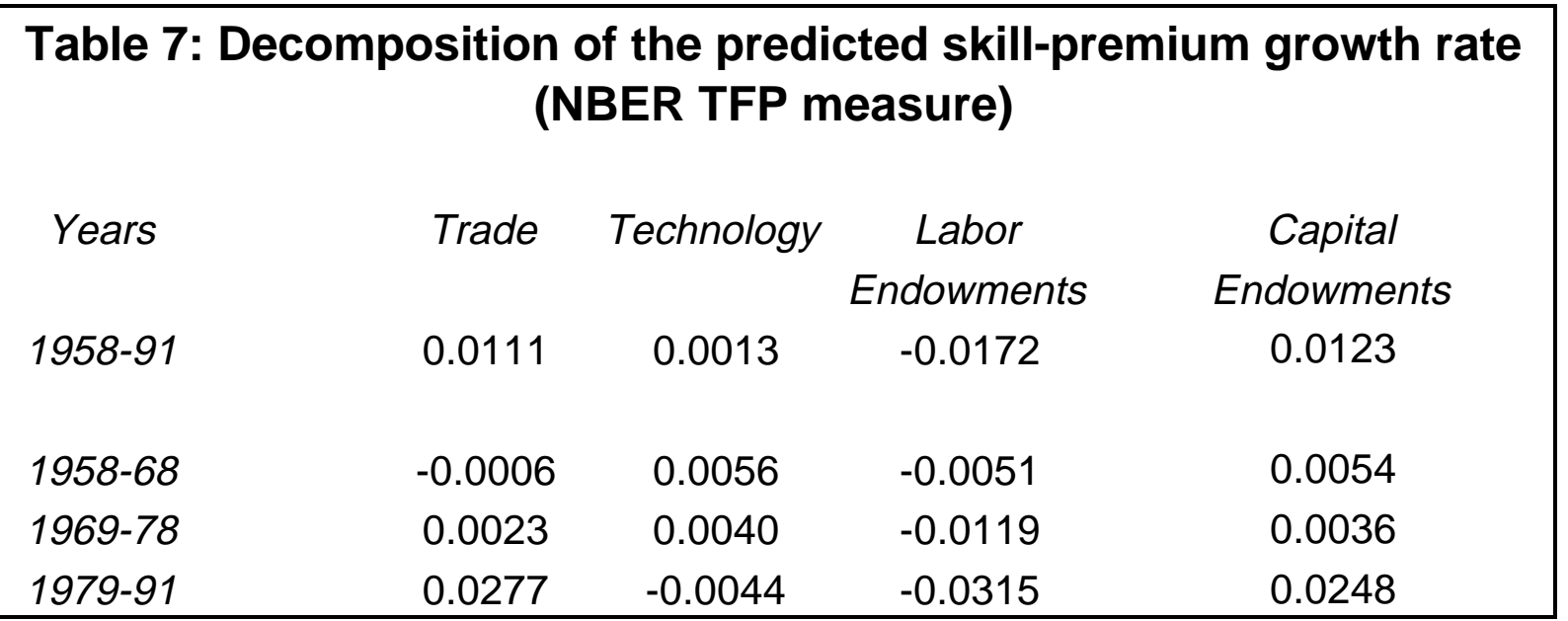


Figure 1: Observed and predicted annual skill premium growth rates in U.S. manufacturing industries, 1958-91

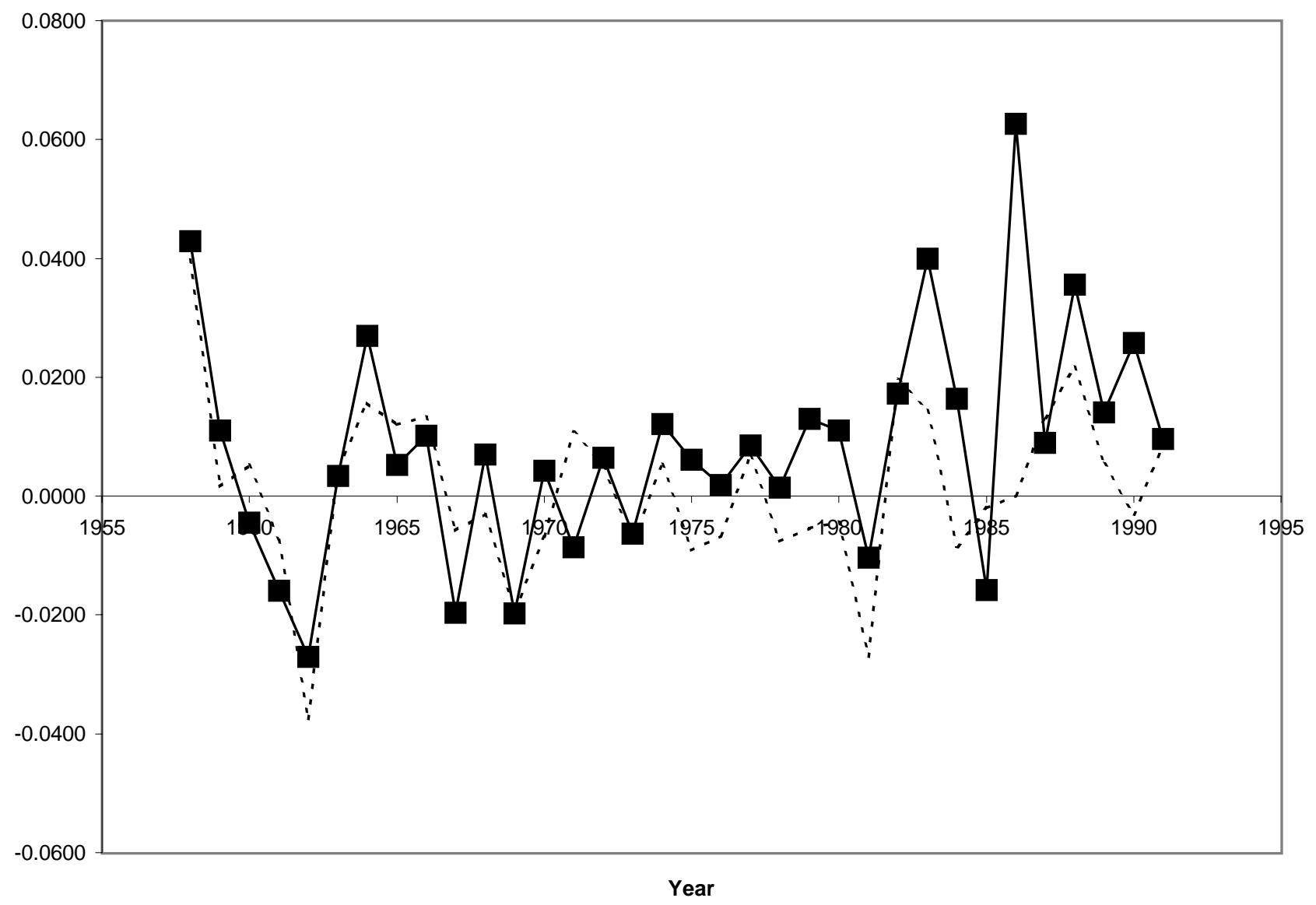


Fig 2: Trade effects on the skill premium

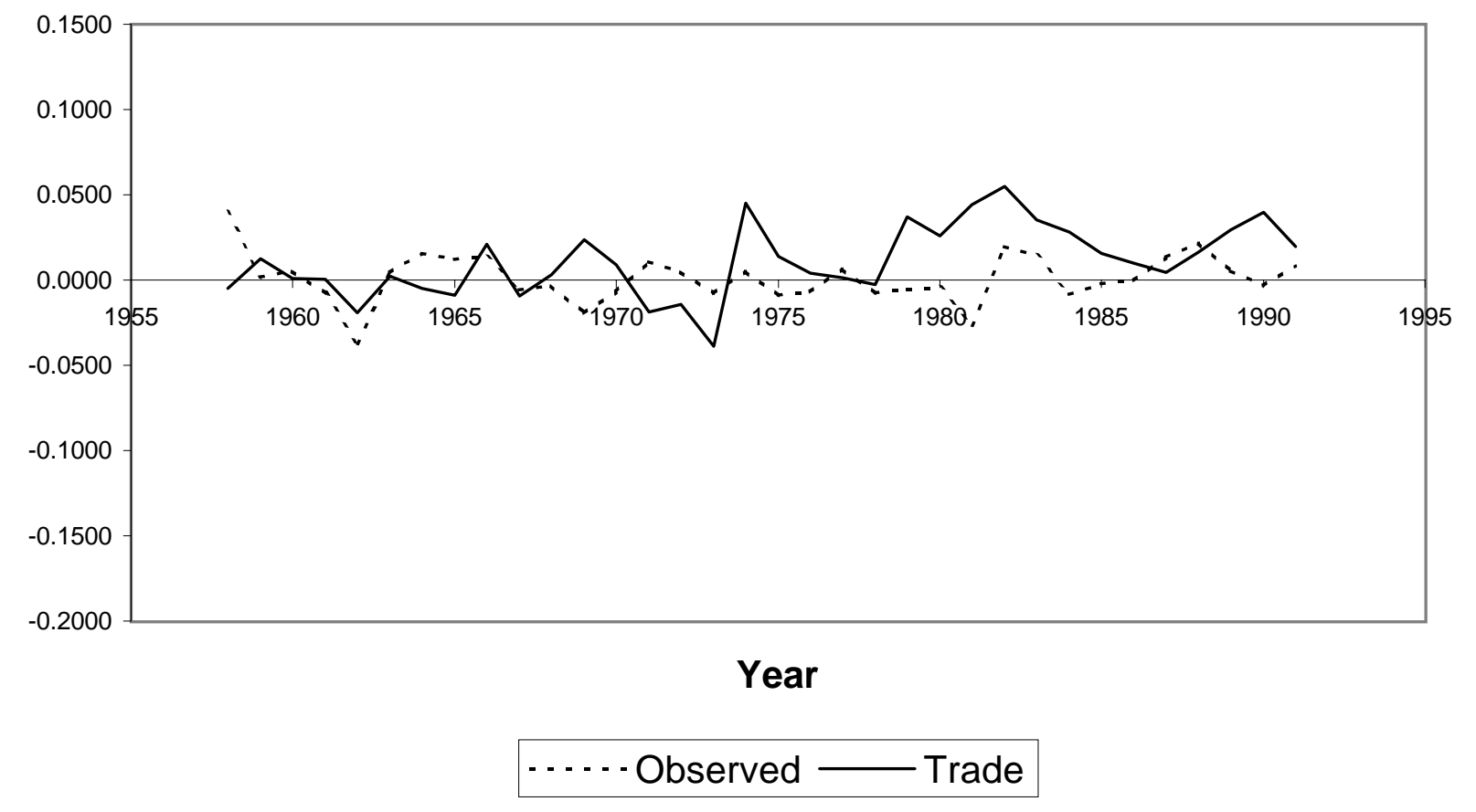

Fig 3: Technology effects on the skill premium

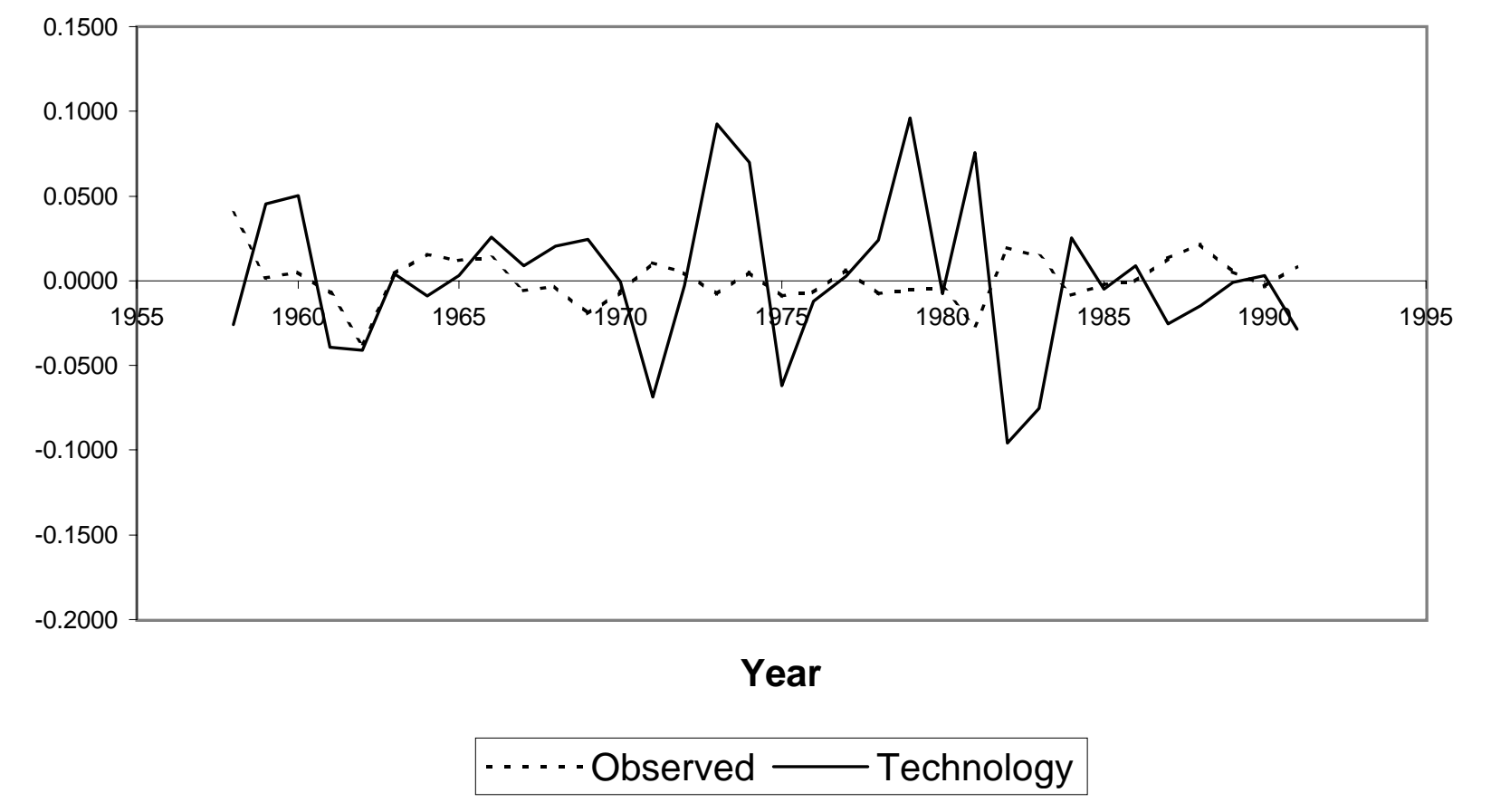



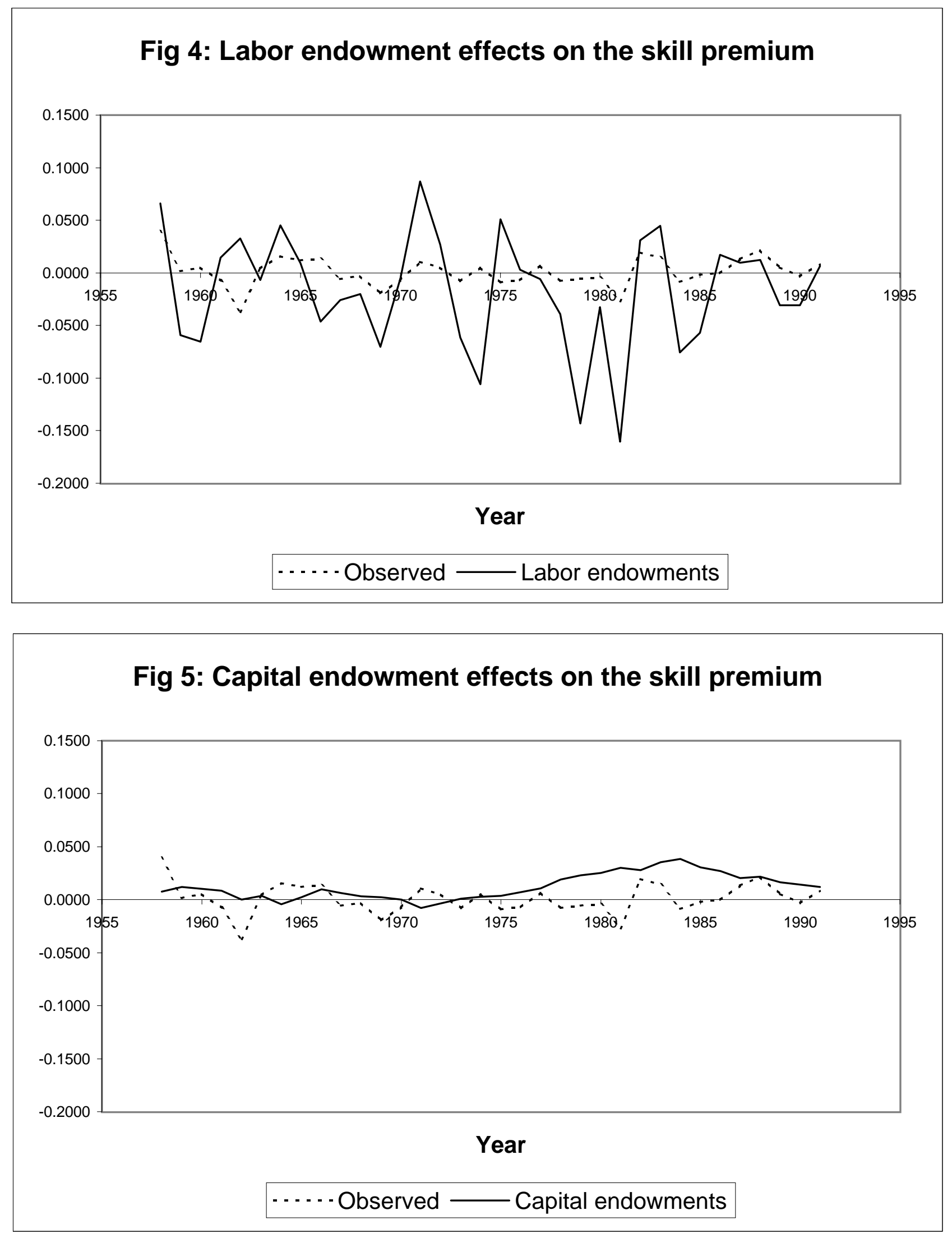
Figure 6: Relative contributions (\%)

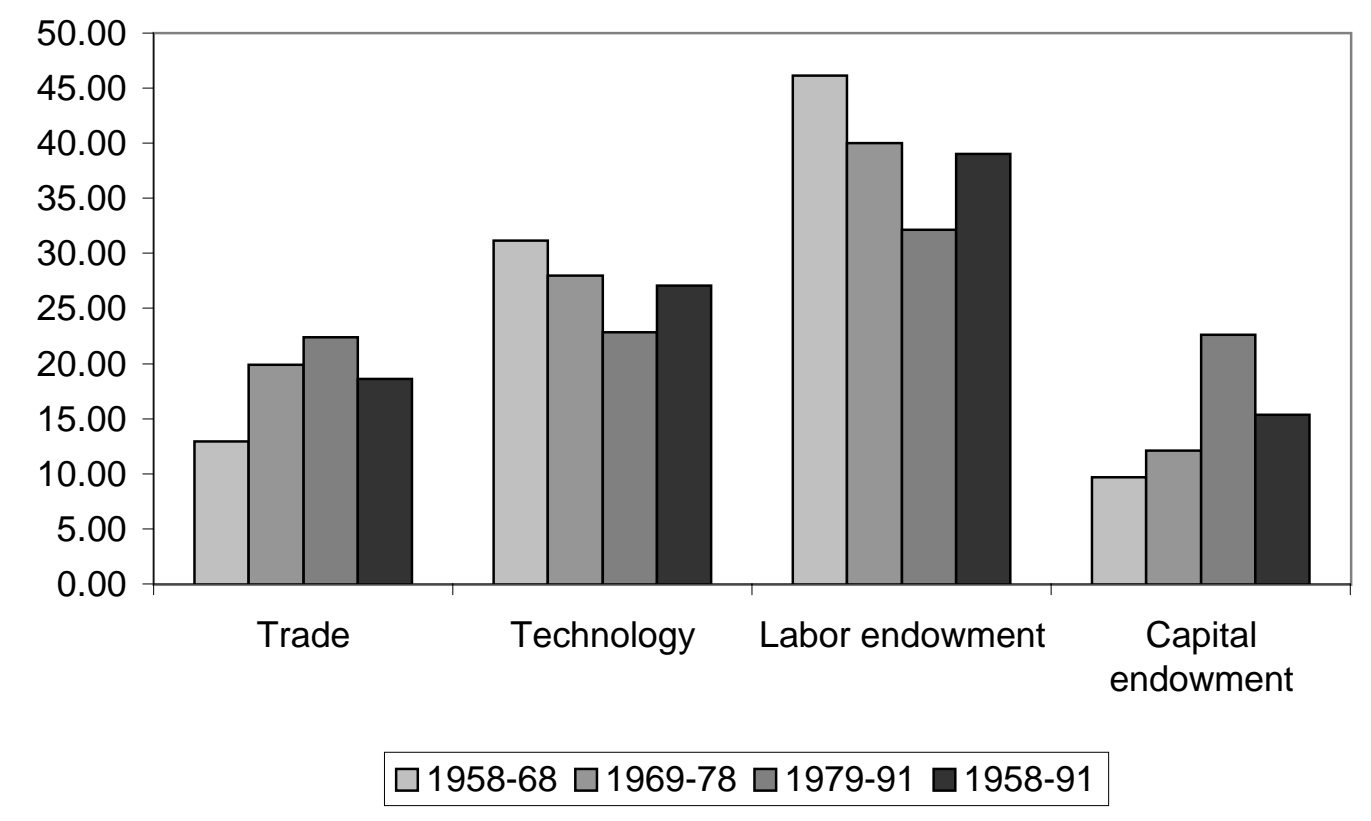

